\title{
Applying lessons learnt from research of child pneumonia management in Vietnam
}

\author{
Phuong NTK ${ }^{1}$, Son $\mathrm{BBB}^{2}$, Chau $\mathrm{NQ}^{3}$, Fitzgerald DA ${ }^{4}$, Graham $\mathrm{SM}^{5,6}$, Marais $\mathrm{BJ}^{7}$
}

${ }^{1}$ Respiratory Department, Da Nang Hospital for Women and Children, Vietnam; 2Discipline of Paediatrics, Hue University of Medicine and Pharmacy, Vietnam; ${ }^{3}$ Vietnam Respiratory Society, Ha Noi, Vietnam; ${ }^{4}$ Respiratory Medicine, The Children's Hospital at Westmead, The University of Sydney, Australia; ${ }^{5}$ Centre for International Child Health, University of Melbourne and Murdoch Children's Research Institute, Royal Children's Hospital, Melbourne, Australia; ${ }^{5}$ International Union Against Tuberculosis and Lung Diseases, Paris, France; ${ }^{6}$ Discipline of Child and Adolescent Health, The Children's Hospital at Westmead, The University of Sydney, Australia

\section{${ }^{*}$ Corresponding author}

Nguyen Thi Kim Phuong

Respiratory Department, Da Nang Hospital for Women and Children

402 Le Van Hien Street

Ngu Hanh Son District

Da Nang

Vietnam

Tel: +84905 561593

Email: phuongty832000@gmail.com

Keywords: Child, pneumonia, lower tract respiratory infections, Vietnam, antibiotic management

Word Count: Text: 2774; Abstract: 190; Figures 1; Tables 3; References 44

Conflict of interests: None to declare 


\section{Educational Aims}

The reader will come to appreciate that in Vietnam:

- Pneumonia is the leading cause of hospital admissions and the main driver of antibiotic use in children less than 5 years of age

- Many admissions do not meet WHO criteria for either 'severe pneumonia' requiring hospitalization, or 'pneumonia' requiring antibiotic treatment

- Use of a pragmatic algorithm to predict 'unlikely bacterial pneumonia' and 'adverse pneumonia outcome' could help to reduce unnecessary hospitalisation and antibiotic use

- Efforts to reduce pneumonia risk and improve outpatient management seems to offer the best value, but has not been sufficiently emphasized in Vietnam.

\section{Future Directions}

For optimal management of pneumonia in Vietnam, there is an urgent need to:

- Improve primary prevention strategies such as promoting exclusive breastfeeding, implementing universal vaccine coverage (including pneumococcal vaccine), and reducing cigarette smoke and air pollution exposure

- Develop and validate pragmatic management algorithms to guide hospital admission and antibiotic use practices

- Reduce irrational antibiotic use and costs through better regulation and antibiotic stewardship

- Build capacity in child lung health and pneumonia management in particular, through better training and critical review of existing practice 


\begin{abstract}
Pneumonia is the leading cause of paediatric hospitalisation in Vietnam, placing a huge burden on the health care system. Pneumonia is also the main reason for antibiotic use in children. Our recent research findings indicate that many hospital admissions for child pneumonia are unnecessary, with inappropriate use of antibiotics being common. Adverse effects related to unnecessary hospital admission are rarely considered and the misuse of antibiotics may be detrimental to the patient and drives increasing antimicrobial resistance. Our observations have demonstrated that children seen at hospital outpatient clinics with 'no fever', 'no consolidation on chest radiograph' and an 'absolute neutrophil count $<5 \times 10^{9} / L$ ' can be classified as 'unlikely bacterial pneumonia' and should not receive antibiotics. Only children with World Health Organisation (WHO) danger signs or consolidation on chest radiograph are at increased risk of 'adverse pneumonia outcome' and should be admitted for inpatient management. Improved models of care will require development and validation of pragmatic management algorithms, and capacity building with evidence-based education and support for healthcare providers who serve as the primary care contact for most patients. Reducing the pneumonia disease burden will also require increased emphasis on primary prevention.
\end{abstract}

Word count: 190 


\section{Background}

Globally, pneumonia is the main cause of disease and death among children ${ }^{1,2}$. Causes of under-five mortality are now mostly concentrated in the neonatal period $(32 \%)$, but pneumonia $(14 \%)$, along with diarrhoea $(10 \%)$ and malaria $(6 \%)$, continues to make a substantial contribution to morbidity and mortality in the post-neonatal period ${ }^{3}$. Most deaths occur in developing countries where access to routine vaccination, adequate sanitation and nutrition, as well as to appropriate antibiotics and oxygen therapy are limited ${ }^{4}$. In 2016, pneumonia accounted for an estimated 650,000 deaths in infant and young children ( $<5$ years) globally, with the vast majority occurring in developing countries; including 57,000 in Southeast and East Asia ${ }^{5}$.

In Vietnam, pneumonia is the leading cause of paediatric hospital admission and places a huge burden on the health care system ${ }^{6,7}$. Although every effort should be made to reduce pneumonia-related morbidity and mortality, the overuse of unnecessary antibiotics and hospitalisations of children with presumed pneumonia is also a major public health challenge in Vietnam associated with adverse health outcomes ${ }^{8,9}$. Rising rates of antimicrobial resistance (AMR) is recognized as a major global threat that may reverse many of the health gains from the last 50 years ${ }^{10}$. Treatment of acute respiratory infections (ARIs) is a major driver of antibiotic use in children, with a preference for the use of broad-spectrum antibiotics as empiric treatment ${ }^{11}$. Excessive and irrational antibiotic use in Vietnam may harm individual patients and increase the AMR risk, limiting future treatment options ${ }^{9}$. Therefore, it is important for clinicians to be familiar with the common pathogens causing pneumonia, the appropriate treatment of these pathogens and the potential negative impacts of unnecessary antibiotic use and hospitalization to improve their rational application.

There is an urgent need to develop optimal and pragmatic models of care. Capacity building through evidence-based training and mentorship of healthcare providers along with operational research are critical to improve clinical care and reduce the irrational use of antibiotics and unnecessary hospitalization, while not increasing the risk of adverse pneumonia-related outcomes. There is also a 
need to emphasize and enhance primary prevention strategies that are often outside the domain of paediatric or respiratory clinicians.

\section{Prevention is better than cure}

Prevention is the most cost-effective intervention to reduce pneumonia-related disease and death in children. Both developing and developed countries have achieved substantial reductions in pneumonia disease burden during the past 10 years ${ }^{3,12}$, which mainly reflect improved socioeconomic conditions, better access to healthcare and wider implementation of immunization against Haemophilus influenzae type b (Hib), measles, whooping cough (pertussis) and Streptococcus pneumoniae. It has been estimated that pneumococcal deaths declined by $51 \%(7-74 \%)$ and Hib deaths by $90 \%$ (78-96\%) from 2000 to 2015 in countries where these vaccines were included in routine vaccination schedules. By the end of 2017, pneumococcal conjugate vaccine (PCV) has been introduced in 141 countries, although access remains limited in many resource-limited settings, including Vietnam ${ }^{13}$. Furthermore, health care workers, pregnant women and vulnerable children, where feasible, should also be considered for seasonal influenza vaccination to reduce influenza risk.

Adequate nutrition is important to improve children's natural defenses, starting with exclusive breastfeeding for the first 4-6 months of life and maintaining breastfeeding for 1-2 years. Breastfeeding reduces the risk of severe pneumonia and the length of the illness if a child does become ill ${ }^{14}$. In Vietnam, only $27 \%$ of mothers reported exclusive breastfeeding during the neonatal period, ${ }^{15}$ and exclusive breastfeeding is rarely sustained beyond 3-4 months of age with less than $10 \%$ of mothers reporting exclusive breast feeding up to 6 months of age 16,17. However, where breastfeeding friendly hospital policies have been implemented uptake is excellent, with up to $60 \%$ of children being exclusively breastfed until 6 months of age ${ }^{8}$. Together with encouraging exclusive breastfeeding, improving obstetric and antenatal care should reduce risks associated with pregnancy and peripartum care, as well as prematurity. Studies have shown that premature babies have nearly double (odds ratio [OR] 1.9; 95\% confidence interval $[\mathrm{Cl}] 1.1-2.9){ }^{18}$ the risk of developing severe pneumonia, or dying from pneumonia (OR 2.4; 95\% Cl 1.7-3.6) $)^{19}$, compared to term babies. 
Addressing environmental factors such as air pollution (both indoor and outdoor) is also important for pneumonia prevention. Cigarette smoke exposure, especially of pregnant women and young children within the home environment, is still very common in Vietnam and has been associated with increased pneumonia risk ${ }^{19-21}$. Findings from an antenatal unit inpatient survey in Vietnam showed that paternal cigarette smoke exposure was the most common modifiable pneumonia risk factor, with nearly $50 \%$ of fathers reported to smoke inside the house ${ }^{22}$. Improving nutrition and conditions of poverty, including crowded living conditions, lack of clean water and irregular hand washing can reduce the incidence of child pneumonia by $16 \%(95 \% \mathrm{Cl} 11-21 \%)^{23}$ and is of particular importance in more disadvantaged areas. Major pneumonia risk factors and suggested strategies for prevention are summarised in Table 1.

\section{Irrational antibiotic use}

Appropriate antibiotic treatment is a key weapon to reduce deaths in children with bacterial pneumonia, but inappropriate use contributes to the development of AMR and an increase in potential adverse effects as well as health care costs. Encouraging rational antibiotic use is a global priority, particularly in Asia, where childhood pneumonia is a major driver of antibiotic use and where access to antibiotics is easy and commonly unrestricted. Potential over-diagnosis and overuse of intravenous (IV) antibiotics have been noted in retrospective and prospective studies in Vietnam and in most other Asian countries ${ }^{7,9}$. Of children admitted with an acute respiratory infection (ARI), more than half had already received an antibiotic pre-admission, often acquired over-the-counter i.e. not prescribed, and nearly all children received antibiotics when admitted to hospital - irrespective of the likelihood of bacterial pneumonia ${ }^{9}$. Children usually remain in hospital and receive antibiotics for a period of 7-10 days, and those started on intravenous (IV) antibiotics are rarely stepped down to an oral one, including those with non-severe pneumonia 7,2425 .

Optimal antibiotic management of childhood pneumonia is challenging in settings where clinicians have limited information regarding the local pathogen and antimicrobial resistance profiles. A comprehensive 
literature review to explore the antibiotic resistance profile of bacteria associated with pneumonia in the Western Pacific region, focusing on Vietnam, showed that optimal child pneumonia management presented an opportunity to reduce excessive antibiotic use in the Western Pacific region ${ }^{26}$. Encouraging rational antibiotic use requires cultural change, improving clinical guidance and the establishment of functional microbiology laboratories to monitor disease aetiology and drug resistance patterns. Removal of inappropriate incentives, with enhanced training and effective enforcement of national regulations would be important to encourage rational antibiotic use in Vietnam. Studies in Vietnam showed that most physicians had a preference for using broad spectrum antibiotics, despite the fact that there has been no evidence that empiric use of antibiotics such as amoxicillin-clavulanate or later generation cephalosporins offered any advantage over amoxicillin ${ }^{27}$ 9,24. Although gradually changing, young paediatricians tend to adopt local rather than evidence-based practice, even if this does not comply with national child pneumonia management guidelines. ${ }^{26}$ Table 2 summarises common causes of irrational antibiotic use identified in Vietnam.

\section{Unnecessary hospitalisation}

A major challenge of pneumonia management and paediatric health care in general in Vietnam is the unnecessary hospital admission of children who present with an acute respiratory tract infection, but do not have symptoms or signs suggestive of severe pneumonia or even non-severe pneumonia. Vietnam lacks pragmatic guidance for hospital admission based on disease severity and available resources. Universal health care coverage extended to all children less than 6 years of age is a great advance and improves health care access, but mechanisms to ensure optimal and efficient utilization have not been established. The World Health Organisation (WHO) case management approach for child pneumonia was primarily developed for countries with a high burden (incidence and mortality) of child pneumonia, settings often with limited resources and over-burdened healthcare facilities. Currently, the WHO recommendation is not widely adopted in Vietnam. Rapid and sustained economic growth has resulted in government services that are commercially incentivized and a rapidly growing private healthcare sector. The fact that doctors in Vietnam aspire to provide individualized patient care that they perceive to be equivalent to tertiary care in high-income countries, and to meet the expectations of the child's family as 
to what constitutes the best available care, e.g. hospitalization with intravenous antibiotics, provide additional complexity 26 .

Observations that children with mild disease are frequently and unnecessarily admitted to hospital are influenced by combinations of all these factors, summarized in Table 2. It is also partially related to a lack of confidence in junior physicians to discharge young children, perceived community expectations and a general fear of adverse outcomes that could attract criticism from senior colleagues, or in other countries litigation ${ }^{26}$. More decentralized models of care are often presented as a solution, but over-diagnosis and over-admission have also been observed with decentralized models of care, if inadequate training is provided to frontline health care workers 28 . Poor alignment of local practices with national and international pneumonia case management guidelines, indicates a need for training and capacity building with a focus on evidence-based practice.

\section{Towards improved models of care}

\section{Better outpatient management with judicious antibiotic use}

Studies in Vietnam showed that nearly $90 \%$ of children hospitalised with ARIs do not fit the criteria for severe pneumonia, i.e. have "non-severe" or "no" pneumonia ${ }^{8}$. WHO recommendations are that those children with "non-severe" pneumonia do not require hospitalization but rather can be managed as outpatients with antibiotics ${ }^{29}$. However, paediatricians in Vietnam feel uncomfortable with the recommendations for hospital admission by the WHO case management approach. They are concerned about the consequences of sending home children with clinical evidence of pneumonia and prefer additional investigation with consideration of chest radiograph (CXR) and/or laboratory findings. We have therefore developed a pragmatic algorithm that takes account of local perspectives and practice, and incorporates our local research findings and current WHO guidance with the aim of changing clinical practice to reduce unnecessary hospital admission and improve antibiotic usage (Figure 1). The recent international PERCH study that included study sites in Thailand and Bangladesh found that elevated 
serum C-reactive protein level (CRP $\geq 40 \mathrm{mg} / \mathrm{L}$ ) was positively associated with confirmed bacterial pneumonia (especially those with Streptococcus pneumoniae and Haemophilus influenzae) and negatively associated with respiratory syncytial virus (RSV) ${ }^{30}$. A study done in northern Vietnam demonstrated that a point-of-care CRP test, using a cut-off of $\geq 50 \mathrm{mg} / \mathrm{L}$, safely reduced unnecessary antibiotic use in children with an ARI presenting to local primary healthcare centres ${ }^{31}$.

\section{Limited hospitalisation with early IV to oral step down}

It is a big challenge to limit unnecessary hospitalisation in Vietnam due to existing funding models, local policies and parental expectations. However, what one can do is to provide and support acquisition of adequate knowledge to physicians on pneumonia severity classification and case management. Information can be disseminated to families through leaflets handed out at hospitals, formal educational campaigns at school and in the local media, and by appropriate use of social media. This information will empower parents and care givers through an understanding of the concept of antimicrobial resistance and an appreciation of both the benefits and risks associated with antibiotic use. Education of both physicians and parents/caregivers is necessary to reduce unnecessary hospital admissions and irrational antibiotic use. Creating a culture of learning where cases with poor outcomes are discussed in a critical but constructive environment is also essential for doctors and institutions to learn from mistakes and find better solutions, rather than admitting all children with pneumonia to hospital for a prolonged course of antibiotics to be on the 'safe side'.

It is important that such reviews should also consider adverse effects resulting from unnecessary care, such as secondary infections acquired in hospital or complications arising from inappropriate intravenous (IV) therapy. In Vietnam, it is not widely applicable that children on IV antibiotics are stepped down to oral treatment once they are stable and improving. Children often complete a full course of IV or oral antibiotics before discharge from hospital irrespective of clinical improvement or treatment response, which partly reflects historical practice and perceived parental expectation. Prolonged administration of IV 
antibiotics remains common practice in many East Asian countries ${ }^{25,32}$. This practice has little regard for the risks and costs (direct and indirect) associated with unnecessary hospital stay and maintaining IV access in a young child ${ }^{33,34}$. Providing $7-10$ days of IV antibiotics essentially reflects established practice in many countries ${ }^{35}$, although there is overwhelming evidence that an early IV to oral switch policy reduces hospital stay, secondary complications and overall healthcare costs without compromising outcomes ${ }^{36,37}$.

To change practice, physicians should be trained in new advances and encouraged to access evidencebased recommendations. Many older physicians who maintain established practice are unable to read foreign scientific literature and even the younger generation of physicians who often can read English, are not encouraged and do not have [government] subsidized or institution-based access to the international medical literature and evidence based search engines [eg "Up to date"]. This is essential to encourage young physicians to adopt evidence-based practice based on literature review rather than adopting existing practice without question. In the broader scheme, readily accessible, government sponsored access to evidence-based information would likely be highly cost-effective for healthcare.

\section{Oxygen supplementation if required}

Oxygen supplementation is important in the management of children with severe pneumonia and hypoxemia. A comprehensive systematic review found that routine evaluation of peripheral oxygen saturation (SpO2) in children with ARI helped to identify those at increased risk of death. Oxygen saturation thresholds $<90-92 \%$ are also associated with an increased risk of death in children with pneumonia ${ }^{38}$ and is considered as an important prognostic indicator ${ }^{39}$. Studies found that children $<5$ years with severe pneumonia and hypoxaemia who received oxygen had significant less treatment failure or death compared to those without oxygen ${ }^{40}$, especially those having oxygen delivered via bubble continuous positive airway pressure (bCPAP) ${ }^{41}$. However, in most district hospitals in Vietnam the use of pulse oximetry and the availability of oxygen remain limited. 


\section{Training and capacity building}

\section{Better pneumonia assessment and management}

Pneumonia classification and management has been included in the Integrated Management of Childhood Illnesses (IMCl) training program for district physicians. This program developed by WHO is well validated and uses a train-the-trainer model to disseminate learning as widely as possible. Guidance provided is that children with respiratory distress or other signs of severe disease should be admitted to the hospital with IV antibiotics, while those with non-severe pneumonia should be discharged home with oral antibiotics. It emphasizes the fact that children with the common cold, who do not have fever or tachypnea should not receive antibiotics. However, since all children with tachypnea are classified as 'pneumonia', while many of them may have viral bronchiolitis, it encourages the use of antibiotics in many children who may not benefit from their use. This is understandable given that the main aim of the IMCI

program is to reduce under- 5 mortality in settings with limited resources. For this very reason many physicians in Vietnam view it as irrelevant to the local setting though the Vietnam Ministry of Heath has adopted and promoted $\mathrm{IMCl}$ training and guidance.

The IMCl approach also fails to consider tuberculosis (TB) as a major cause of pneumonia and under-5 mortality and provides no guidance on the management of childhood asthma. There is scope to develop a training program focused child lung health, aiming to strengthen clinicians' capacity to manage common conditions affecting child lung health in order to improve both survival and long-term quality of life. Five main areas to consider include pneumonia, bronchiolitis, croup, asthma and tuberculosis. Training should provide a brief overview of the target conditions with pragmatic guidance that focuses on a basic understanding of disease pathology and etiology, improved prevention, early and accurate diagnosis, and optimal evidence-based management.

\section{Conclusion}


Pneumonia is the leading cause of childhood morbidity, mortality and hospital admissions in Vietnam, placing a huge burden on the health care system. Approaches to reduce pneumonia-related morbidity and mortality have promoted widespread antibiotic use. However, rising rates of antimicrobial resistance and global commitments to reduce irrational antibiotic use require a critical re-assessment of existing practices. A better understanding of relevant pneumonia risk factors, as well as hospital admission and management practices, is required to identify strategies that may limit unnecessary antibiotic use, optimize patient outcomes and reduce the overall burden on the health care system. Improved training and capacity building of district-level physicians is considered a key intervention to improve pneumonia case management in Vietnam, ideally with a broader focus on lung health to also improve asthma and tuberculosis care. 
Table 1. Overview of pneumonia risk factors and strategies to consider for pneumonia prevention*

\begin{tabular}{|l|l|l|}
\hline Risk factor & Specific determinants & Recommendation at individual level \\
\hline $\begin{array}{l}\text { Lack of } \\
\text { breastfeeding }\end{array}$ & $\begin{array}{l}\text { Exclusive breastfeeding } \\
\text { Duration of breastfeeding }\end{array}$ & $\begin{array}{l}\text { Exclusive breastfeeding for the first } 6 \text { months and aiming } \\
\text { to maintain breastfeeding for 2 years } \\
\text { All obstetric/neonatal care to be "baby friendly" and } \\
\text { supportive of breastfeeding }\end{array}$ \\
\hline $\begin{array}{l}\text { Incomplete } \\
\text { vaccination }\end{array}$ & $\begin{array}{l}\text { Lack of immunization } \\
\text { against Haemophilus } \\
\text { influenzae type b (Hib), } \\
\text { pneumococcus, measles } \\
\text { and whooping cough }\end{array}$ & $\begin{array}{l}\text { Full immunization with all vaccines in the national } \\
\text { immunization program } \\
\text { Encouraging uptake with seasonal influenza and } \\
\text { pneumococcal vaccine }\end{array}$ \\
\hline $\begin{array}{l}\text { Cigarette } \\
\text { smoke and air } \\
\text { pollution } \\
\text { exposure }\end{array}$ & $\begin{array}{l}\text { Cigarette smoke exposure } \\
\text { Indoor air pollution } \\
\text { Outdoor air pollution }\end{array}$ & $\begin{array}{l}\text { Reducing cigarette smoking prevalence and household } \\
\text { exposure } \\
\text { Use of affordable clean indoor stoves } \\
\text { Improving the air quality in our cities }\end{array}$ \\
\hline $\begin{array}{l}\text { Malnutrition } \\
\text { and conditions } \\
\text { of poverty }\end{array}$ & $\begin{array}{l}\text { Protein and calorie intake } \\
\text { Living conditions } \\
\text { Hygiene and sanitation } \\
\text { Maternal education } \\
\text { Health care access }\end{array}$ & $\begin{array}{l}\text { Ensuring a well-balanced diet } \\
\text { Regular hand washing } \\
\text { Routine cough etiquette } \\
\text { Keep the house clean and well ventilated } \\
\text { Education, including heath education, for all }\end{array}$ \\
\hline $\begin{array}{l}\text { Underlying } \\
\text { conditions \& } \\
\text { unnecessary } \\
\text { hospitalisation }\end{array}$ & $\begin{array}{l}\text { Prematuriy and birth } \\
\text { defects } \\
\text { Vertical HIV transmission } \\
\text { Nosocomial disease } \\
\text { transmission }\end{array}$ & $\begin{array}{l}\text { Improve obstetric and neonatal care to minimise chronic } \\
\text { lung disease } \\
\text { Minimise vertical HIV transmission and optimise HIV } \\
\text { care** } \\
\text { Minimise unnecessary and prolonged hospitalization; } \\
\text { ensure that nosocomial infection risks are considered and } \\
\text { that optimal infection control measures are in place }\end{array}$ \\
\hline
\end{tabular}

HIV - human immunodeficiency virus

${ }^{*}$ Adapted from ${ }^{42}$

${ }^{* *}$ Rates of vertical HIV transmission is low in Vietnam, but it is a major challenge in some settings such as sub-Saharan Africa. Universal testing in pregnancy is warranted to ensure effective prevention and management of mother to child HIV transmission, but testing rates remain low throughout Asia. 
Table 2. Identified causes of irrational antibiotic use and unnecessary hospitalisation in Vietnam*

\begin{tabular}{|c|c|}
\hline Issue & Identified causes \\
\hline $\begin{array}{l}\text { Irrational } \\
\text { antibiotic use }\end{array}$ & $\begin{array}{l}\text { - Limited adherence with available national and international guidelines } \\
\text { - Adoption of historical practices without careful review of the latest evidence } \\
\text { - A strong belief (by physicians and parents) that antibiotics are effective and } \\
\text { that intravenous (IV) administration is better than oral } \\
\text { - Afraid of an adverse outcome and being criticized/blamed for not offering } \\
\text { effective treatment - no consideration of benefit:risk ratios } \\
\text { - Preference for a broad-spectrum ("more powerful") antibiotics, often promoted } \\
\text { by pharmaceutical companies } \\
\text { - Lack of microbiological support to guide better targeted antibiotic use } \\
\text { - Physicians have no time and confidence to explain the rationale for not using } \\
\text { antibiotics to parents } \\
\text { - A need to satisfy parent and hospital manager expectations, which are all } \\
\text { influenced by existing incentives and funding models } \\
\text { - No consideration of the adverse effects associated with antibiotic use or } \\
\text { unnecessary IV administration }\end{array}$ \\
\hline $\begin{array}{l}\text { Unnecessary } \\
\text { hospitalisation }\end{array}$ & $\begin{array}{l}\text { - Local policies and funding models that encourage unnecessary hospital } \\
\text { admission } \\
\text { - Junior physicians at emergency department (ED) and outpatient clinics are not } \\
\text { confident to discharge patients home, especially those presenting to ED after } \\
\text { hours } \\
\text { - Fear of perceived inadequate treatment that may not meet parental } \\
\text { expectations or lead to an adverse outcome } \\
\text { - No consideration of the adverse effects associated with unnecessary } \\
\text { hospitalization }\end{array}$ \\
\hline
\end{tabular}

${ }^{*}$ Adapted from ${ }^{9,24,26}$ 
Table 3. Priorities for training and capacity building in child lung health

1) Understanding of the etiology of common respiratory infections

2) Appreciating key aspects of disease pathology, which explains the rationale of current treatment approaches

3) Being aware of the principles and practice of evidence-based medicine

4) Focusing on the most common conditions encountered in pediatric practice and those where existing practice in Vietnam is not aligned with national and international guidance - including

- Pneumonia

- Bronchiolitis / Croup

- Asthma

- Tuberculosis 
Figure 1. Suggested algorithm to guide outpatient management a (adapted from ${ }^{43}$ )

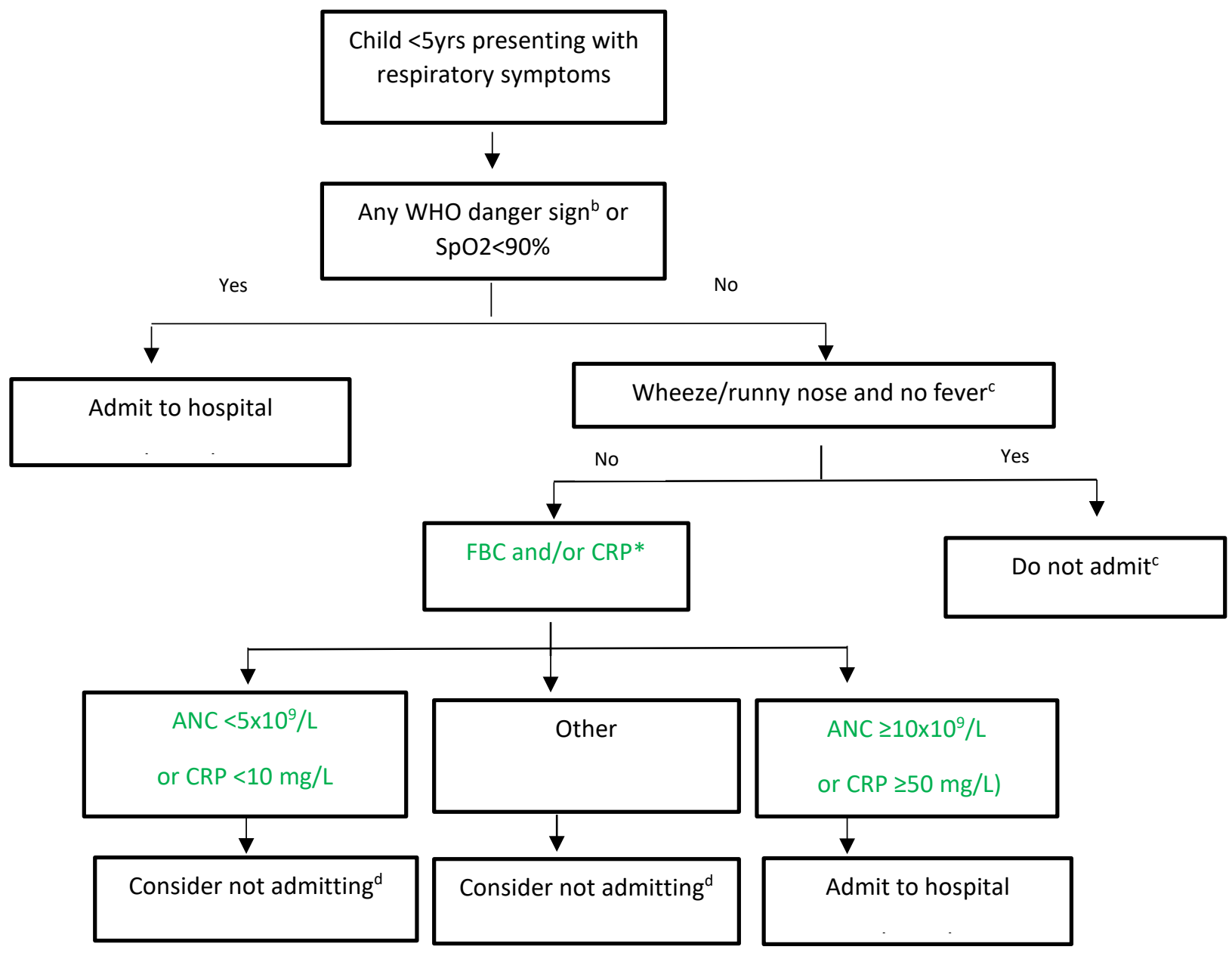

ANC - absolute neutrophil count; CRP - C reactive protein; SpO2 - peripheral oxygen saturation; WHO World Health Organization

alncorporating study findings, existing WHO guidance and previous findings from Vietnam that used CRP values to guide rational antibiotic use ${ }^{31}$

bIncluding inability to drink or breastfeed, lethargy or convulsions, respiratory distress (grunting or nasal flaring), severe malnutrition

${ }^{\mathrm{c} A s}$ per $\mathrm{WHO}$ recommendation ${ }^{44}$

${ }^{\mathrm{d} A d m i t}$ and consider antibiotics if any deterioration or relevant clinical concern

${ }^{*}$ A chest radiograph may provide additional information in settings where it is readily available, but its interpretation is subjective and correlation with underlying pathogen aetiology is limited. 


\section{References}

1. Walker CLF, Rudan I, Liu L, et al. Global burden of childhood pneumonia and diarrhoea. Lancet 2013;381:1405-16.

2. Li Liu, Shefali Oza, Dan Hogan, et al. Global, regional, and national causes of under-5 mortality in 2000-15: an updated systematic analysis with implications for the Sustainable Development Goals. Lancet 2016;16:31593-8.

3. GBD Compare Data Visualization. http://vizhub.healthdata.org/gbd-compare (acessed 17 August 2020).

4. Izadnegahdar R, Cohen AL, Klugman KP, Qazi SA. Childhood pneumonia in developing countries. Lancet Respir Med 2013;1:574-84.

5. GBD 2016 Lower Respiratory Infections Collaborators. Estimates of the global, regional, and national morbidity, mortality, and aetiologies of lower respiratory infections in 195 countries, 19902016: a systematic analysis for the Global Burden of Disease Study 2016. Lancet Infect Dis 2018;18:1191210.

6. Yoshida L-M, Suzuki M, Thiem VD, et al. Population based cohort study for pediatric infectious diseases research in Vietnam. Trop Med Health 2014;42:S47-S58.

7. Nguyen TKP, Nguyen DV, Truong TNH, Tran MD, Graham SM, Marais BJ. Disease spectrum and management of children admitted with acute respiratory infection in Viet Nam. Trop Med Int Health 2017;22:688-95.

8. Nguyen PT, Tran TH, Fitzgerald DA, Tran ST, Graham SM, Marais BJ. Characterisation of children hospitalised with pneumonia in central Vietnam: A prospective study. Eur Respir J 2019;1:1802256.

9. Nguyen TKP, Tran TH, Fitzgerald DA, Graham SM, Marais BJ. Antibiotic use in children hospitalsied with pneumonia in central Vietnam: A prospective study (Epub ahead of print). Arch Dis Child 2019.

10. Hill-Cawthorne G, Negin J, Capon T, et al. Advancing Planetary Health in Australia: focus on emerging infections and antimicrobial resistance. BMJ Glob Health 2019;4:e001283.

11. WHO. Antimicrobial resistance: global report on surveillance. http://wwwwhoint/drugresistance/documents/surveillancereport/en/ (accessed 20 August 2020) 2014.

12. Sazawal S, Black RE, Group PCMT. Effect of pneumonia case management on mortality in neonates, infants, and preschool children: a meta-analysis of community-based trials. Lancet Infect Dis 2003;3:547-56.

13. Wahl B, O'Brien KL, Greenbaum A, et al. Burden of Streptococcus pneumoniae and Haemophilus influenzae type $b$ disease in children in the era of conjugate vaccines: global, regional, and national estimates for 2000-15. Lancet Glob Health 2018;6:e744-e57.

14. Horta BL, Victora CG. Short-Term Effects of Breastfeeding: A Systematic Review on the Benefits of Breastfeeding on Diarrhea and Pneumonia Mortality. WHO; 2013.

15. WHO. Workshop on Validation of Early Essential Newborn Care Progress, Manila, Philippines, 12-13 August 2015: report: Manila: WHO Regional Office for the Western Pacific; 2015.

16. Duong DV, Binns CW, Lee AH. Breast-feeding initiation and exclusive breast-feeding in rural Vietnam. Public Health Nutr 2004;7:795-9.

17. Thu HN, Eriksson B, Khanh TT, et al. Breastfeeding practices in urban and rural Vietnam. BMC Public Health 2012;12:964.

18. Jackson S, Mathews $\mathrm{KH}$, Pulanić $\mathrm{D}$, et al. Risk factors for severe acute lower respiratory infections in children-a systematic review and meta-analysis. Croat Med J 2013;54:110-21. 
19. Sonego M, Pellegrin MC, Becker G, Lazzerini M. Risk factors for mortality from acute lower respiratory infections (ALRI) in children under five years of age in low and middle-income countries: a systematic review and meta-analysis of observational studies. PloS one 2015;10:e0116380.

20. Shibata T, Wilson JL, Watson LM, et al. Childhood acute respiratory infections and household environment in an Eastern indonesian urban setting. Int J Environ Res Public Health 2014;11:12190-203.

21. Vanker A, Barnett $W$, Brittain $K$, et al. Antenatal and early life tobacco smoke exposure in an African birth cohort study. Int J Tuberc Lung Dis 2016;20:729-37.

22. Phuong NT, Hoang TT, Foster K, Roberts CL, Marais BJ. Exploring pneumonia risk factors in Vietnamese infants: a survey of new mothers. BMJ Paediatr Open 2017;1.

23. Rabie $T$, Curtis V. Handwashing and risk of respiratory infections: a quantitative systematic review. Trop Med Int Health 2006;11:258-67.

24. Nguyen TKP, Tran TH, Truong TTH, Nguyen TV, Graham SM, Marais BJ. Paediatric use of antibiotics in children with community acquired pneumonia: A survey from Da Nang, Vietnam. J Paediatr Child Health 2019;55:1329-34.

25. Mi X, Li W, Zhang L, et al. The drug use to treat community-acquired pneumonia in children: $\mathrm{A}$ cross-sectional study in China. Medicine 2018;97.

26. Nguyen TKP, Tran TH, Pham HV, Graham SM, Marais BJ. Encouraging rational antibiotic use in childhood pneumonia - focus on the Western Pacific region. Pneumonia 2017;9:7.

27. Gerber JS, Ross RK, Bryan M, et al. Association of Broad-vs Narrow-Spectrum Antibiotics With Treatment Failure, Adverse Events, and Quality of Life in Children With Acute Respiratory Tract Infections. JAMA 2017;318:2325-36.

28. Gowraiah V, Awasthi S, Kapoor R, et al. Can we distinguish pneumonia from wheezy diseases in tachypnoeic children under low-resource conditions? A prospective observational study in four Indian hospitals. Arch Dis Child 2014;99:899-906.

29. WHO. Revised WHO classification and treatment of childhood pneumonia at health facilities. Geneva: World Health Organization 2014.

30. Higdon MM, Le T, O'brien KL, et al. Association of C-reactive protein with bacterial and respiratory syncytial virus-associated pneumonia among children aged $<5$ years in the PERCH Study. Clin Infect Dis 2017;64:S378-S86.

31. Do NT, Ta NT, Tran NT, et al. Point-of-care C-reactive protein testing to reduce inappropriate use of antibiotics for non-severe acute respiratory infections in Vietnamese primary health care: a randomised controlled trial. Lancet Global Health 2016;4:633-41.

32. Wei W, Wang XF, Liu JP, et al. Status of antibiotic use in hospitalized children with communityacquired pneumonia in multiple regions of China. Chinese journal: Zhonguo Dang Dai Er Ke Za Zhi 2019;21:11-7.

33. Greenberg D, Givon-Lavi N, Sadaka Y, Ben-Shimol S, Bar-Ziv J, Dagan R. Short-course antibiotic treatment for community-acquired alveolar pneumonia in ambulatory children: a double-blind, randomized, placebo-controlled trial. Pediatr Infect Dis J 2014;33:136-42.

34. Ginsburg AS, Mvalo T, Nkwopara E, et al. Placebo vs amoxicillin for nonsevere fast-breathing pneumonia in Malawian children aged 2 to 59 months: a double-blind, randomized clinical noninferiority trial. JAMA Pediatr 2019;173:21-8.

35. Nascimento-Carvalho AC, Nascimento-Carvalho CM. Clinical management of communityacquired pneumonia in young children. Expert Opin Pharmacother 2018;20:435-42.

36. Shrayteh ZM, Rahal MK, Malaeb DN. Practice of switch from intravenous to oral antibiotics. Springerplus 2014;3:717.

37. Addo-Yobo E, Anh DD, El-Sayed HF, et al. Outpatient treatment of children with severe pneumonia with oral amoxicillin in four countries: the MASS study. Trop Med Int Health 2011;16:9951006. . 
38. Lazzerini $\mathrm{M}$, Sonego $\mathrm{M}$, Pellegrin MC. Hypoxaemia as a mortality risk factor in acute lower respiratory infections in children in low and middle-income countries: systematic review and metaanalysis. PloS one 2015;10:e0136166.

39. Marangu D, Zar HJ. Childhood pneumonia in low-and-middle-income countries: An update. Paediatr Respir Rev 2019;32:3-9.

40. Duke T, Mgone J, Frank D. Hypoxaemia in children with severe pneumonia in Papua New Guinea [oxygen therapy in children]. Int J Tuberc Lung Dis 2001;5:511-9.

41. Chisti MJ, Salam MA, Smith JH, et al. Bubble continuous positive airway pressure for children with severe pneumonia and hypoxaemia in Bangladesh: an open, randomised controlled trial. Lancet 2015;386:1057-65.

42. Nguyen TKP, Tran TH, Roberts CL, Fox GJ, Graham SM, Marais BJ. Risk factors for child pneumonia-focus on the Western Pacific Region Paediatr Respir Rev 2017;21:95-101.

43. Nguyen TKP, Tran TH, Tran ST, Fitzgerald DA, Graham SM, Marais BJ. Predictors of 'unlikely bacterial pneumonia'and 'adverse pneumonia outcome'in children admitted to hospital in central Vietnam (Epub ahead of print). Clin Infect Dis 2019.

44. WHO. Recommendations for management of common childhood conditions: evidence for technical update of pocket book recommendations: newborn conditions, dysentery, pneumonia, oxygen use and delivery, common causes of fever, severe acute malnutrition and supportive care. Geneva: World Health Organization, Department of Child and Adolescent Heath and Developement. Evidence for technical update of pocket book recommendations 2012 . 


\section{University Library}

\section{- M M N E R VA A gateway to Melbourne's research publications}

Minerva Access is the Institutional Repository of The University of Melbourne

Author/s:

Nguyen, TKP;Bui, BBS;Ngo, QC;Fitzgerald, DA;Graham, SM;Marais, BJ

Title:

Applying lessons learnt from research of child pneumonia management in Vietnam

Date:

2021-09-13

Citation:

Nguyen, T. K. P., Bui, B. B. S., Ngo, Q. C., Fitzgerald, D. A., Graham, S. M. \& Marais, B. J. (2021). Applying lessons learnt from research of child pneumonia management in Vietnam. PAEDIATRIC RESPIRATORY REVIEWS, 39, pp.65-70. https://doi.org/10.1016/ j.prrv.2020.09.005.

Persistent Link:

http://hdl.handle.net/11343/257659 